\title{
Assessment of Membrane Erythrocyte Cholesterol Level in Sickle Cell Disease
}

\author{
J. A. N. Mwelo1 ${ }^{*}$, Z. Diakiese ${ }^{1}$, L. Diyi ${ }^{2}$, O. Nzingula ${ }^{1}$, N. Misengabu ${ }^{2}$, \\ G. Inkalaba1, M. Luvandu', K. K. Kodondi1
}

\author{
${ }^{1}$ Laboratory of Biochemistry-Hematology, Faculty of Pharmaceutical Sciences, University of Kinshasa (UNIKIN), Kinshasa, DR Congo \\ ${ }^{2}$ Institute for Research in Health Sciences (IRSS), Kinshasa, DR Congo \\ ${ }^{3}$ Higher Institute of Medical Sciences (ISTM), Nutrition Section, Kinshasa, DR Congo \\ Email: *anatolelingeba@yahoo.fr
}

How to cite this paper: Mwelo, J.A.N. Diakiese, Z., Diyi, L., Nzingula, O., Misengabu, N., Inkalaba, G., Luvandu, M. and Kodondi, K.K. (2020) Assessment of Membrane Erythrocyte Cholesterol Level in Sickle Cell Disease. Journal of Biosciences and Medicines, 8, 16-22.

https://doi.org/10.4236/jbm.2020.811003

Received: August 10, 2020

Accepted: November 6, 2020

Published: November 9, 2020

Copyright (c) 2020 by author(s) and Scientific Research Publishing Inc. This work is licensed under the Creative Commons Attribution International License (CC BY 4.0).

http://creativecommons.org/licenses/by/4.0/

\begin{abstract}
Objective: The aim of this study was to assess the level of erythrocyte membrane cholesterol in sickle cell patients, which is one of the essential parameters of membrane fluidity that contributes to understanding the hemolytic state of the erythrocyte. Methods: We worked with blood specimens from 20 controls and 50 sickle cell patients. The blood count and the isoelectric focusing (IEF) were performed on the samples in order to select them. The titration of the erythrocyte membrane cholesterol was made after washing and lysing the erythrocytes with the hemolyzing solution (EDTA, 2 MercaptoEthanol, NADP, $\mathrm{NaOH}$ ). The cholesterol level was assessed by the enzymatic colorimetric method. The results were analyzed by Student's test. Results: We worked with 16 control subjects with a hemoglobin status and a normal hemogram. The evaluation of the erythrocyte membrane cholesterol level of the samples allows us to define the reference interval $(\alpha=0.05)$ at $17.55 \pm 3.83$ $\mathrm{mg}$ of cholesterol/g of hemoglobin. The erythrocyte membrane cholesterol levels of sickle cell patients found in this study were $11.58 \pm 2.98 \mathrm{mg}$ cholesterol/g of hemoglobin. In this study, 38 sickle cell patients (76\%) were found with a low erythrocyte membrane cholesterol level compared to the reference interval. Statistical analysis showed that there was a significant difference $(\alpha=$ $5 \%$ ) between the erythrocyte membrane cholesterol level of normal subjects and sickle cell patients. Conclusion: Most of the sickle cells patients had a decreased erythrocyte membrane cholesterol level. This reduces the membrane fluidity making the erythrocyte membrane rigid and more fragile. This may be one of the factors responsible for the lyses of erythrocytes.
\end{abstract}

\section{Keywords}

Cholesterol, Membrane Fluidity, Sickle Cell Anemia, Erythrocytes 


\section{Introduction}

Sickle cell disease is a genetic disorder of the hemoglobin, contained in red blood cells, which is used to carry oxygen throughout the body. This widespread genetic disease affects more than 50 million people worldwide [1] [2]. Sickle cell disease is particularly common in populations of Caribbean, African and Mediterranean origin. It is also present in India and South America. In Central Africa, $30 \%$ of the population is affected [3]. Due to the migratory phenomenon of the population, the disease is currently found all over the world [3].

Pathophysiologically, the disease is characterized by anemia, susceptibility to infections, and pain caused by poor blood circulation and by lack of tissue oxygenation. However, the clinic signs are very variable from one person to another, and during the time [4] [5].

The sickle cell disease evolves in two forms: the homozygote form which represents the most severe form, and the heterozygote form which is almost asymptomatic with sometimes symptoms related to sickling [2]. The disease is considered to be a multifactorial and multidisciplinary disease.

The chronic manifestations of sickle cell disease produce a delay in height and weight gains. This nutritional deficits, in sub-Saharan Africa, are real public health issue since the majority of the population is poor and cannot access healthcare in general and sickle cell therapy in particular [1] [2].

Among the clinical manifestations, the hemolytic anemia exposes sickle cell patients to repeated transfusions. Indeed, cholesterol plays several role in the organism, and it is one of the constituents of plasma membranes that contributes to both fluidity and membrane stability [6] [7]. Cholesterol molecules interposed between those of phospholipids prevent the coalescence of phospholipid chains and crystallization. The lack of membrane cholesterol could dramatically reduce membrane fluidity [6] [8]. The fluidity of the membrane depends on its lipid composition with key role play by cholesterol [8]. Cholesterol strengthens the membrane. This has been shown in some study with cell lines that do not synthesize cholesterol. It was observed that these cells rapidly undergo lysis because of the very great fragility of their membrane. However, the same experiment carried out in the presence of cholesterol in the culture medium showed inhibition of cytolysis. The cholesterol has a buffer effect: it makes the rigid membranes more fluid [9]. Cholesterol therefore ensures the control of membrane fluidity. It also affects the function of the membrane by influencing the activities of certain membrane proteins [7] [10].

Sickle cell disease patients have red blood cells predisposed to lysis, resulting in of hemolytic anemia. The integrity of the membrane is essential for the proper functioning of the cell. This is particularly true for the red blood cell witch play an essential role in oxygen transport [11]. Sickle cell disease being a multifactorial disease, we postulate that the erythrocyte membrane cholesterol level of sickle cell patients will be low compared to those of normal subjects. This low level of membrane cholesterol could decrease the membrane fluidity of erythro- 
cyte.

Further, the membrane fluidity depends directly on the lipid composition in general and in particular on cholesterol level. Consequently, the cholesterol level would also be abnormal during sickle cell disease [12]. In this context, we have found useful to evaluate the erythrocyte membrane cholesterol level in sickle cell patients, for a better understanding of the hemolytic state of these patients.

\section{Material and Methods}

This study took place from January to March 2018. It was carried out on 50 sickle cell patients ( 32 females and 18 males) whose age varied between 2 and 37 years old. All of them had not been transfused at least three months before the study. The sickle cell patient were recruited at "Centre Mixte d'Anémie SS: CMMASS", a public institution specializing in the medical care of children with sickle cell disease. The control has not suffer from any hematological disease including sickle cell anemia (homozygote or heterozygote). Electro-focusing and blood count were performed for all samples before any selection. Only samples with a normal blood count and normal hemoglobin status were retained.

\section{Screening of hemogram}

The hemogram was used to select samples. The hemogram is a basic hematological exploration [13]. It is a very important and useful examination for the diagnosis of anemias as well as their classification [14] [15]. In the blood count, we were interested in hemoglobin, hematocrit as well as erythrocyte constants to select samples.

\section{Isoelectric focusing}

The isoelectric focusing (IEF) electrophoresis (refrigerator: Caron $2050 \mathrm{w}$; migration tank: Amershan Biosciences; voltage generator: electrophoresis power supply-EPS $3501 \mathrm{XL}$ ) was used to determine the status of the hemoglobin of samples and to confirm that of sickle cell patient. The isoelectric focusing electrophoresis has the advantage of high resolution because the hemoglobin are separated according to their isoelectric points in a stable, narrow, $\mathrm{pH}$ gradient (6 8) [16].

The lysis of the red blood cells was carried out with a lysing solution (Trypton $0.1 \mathrm{~g}$; KCN $50 \mathrm{mg}$; Na azide $100 \mathrm{mg} ; \mathrm{H}_{2} \mathrm{O} 100 \mathrm{~mL}$ ). The electrode solutions consisted of (Cathode: $0.01 \mathrm{M} \mathrm{NaOH}$; Anode: $0.02 \mathrm{M} \mathrm{H}_{3} \mathrm{PO}_{4}$ ). The migration conditions were as follows: Voltage $1500 \mathrm{~V}$, Amperage: $100 \mathrm{~mA}$; Power $10 \mathrm{w}$. After migration, a successive washing was carried out first with 10\% TCA and then twice with distilled water.

\section{Preparation of sample}

We previously washed the red blood cells. This washing eliminates the extra erythrocyte cholesterol likely to yield biased results. We added $1 \mathrm{ml}$ of whole blood to $2 \mathrm{ml}$ of physiological solution. The tube was centrifuged at $2000 \mathrm{rpm}$ for 5 minutes. The supernatant was then decanted. The operation was repeated three times. 
Since cholesterol is part of the cell membrane, $50 \mu \mathrm{L}$ of the red blood cell pellet was added to $950 \mu \mathrm{L}$ of a lysing solution (EDTA, 2 Mercapto-Ethanol, NADP, $\mathrm{NaOH}$ ). This was used for the assessment of hemoglobin and membrane cholesterol.

\section{Membrane cholesterol levels}

The cholesterol titration was performed for both control subjects and sickle cell patients. It was evaluated by the enzymatic method with three enzymes: cholesterol esterase, cholesterol oxidase and peroxidase. $10 \mu \mathrm{L}$ of the lysed erythrocyte solution were added to $1000 \mu \mathrm{L}$ of the enzymes solution and incubated in darkness for exactly 10 minutes. After the reaction, quinoneimin (a pink color complex) is formed. The color intensity was read by a spectrophotometer $(\mathrm{Hu}-$ malyser 2000) at $500 \mathrm{~nm}$ against a reagent blank. The coloration is directly proportional to the concentration of cholesterol in the sample [17]. Blood Cholesterol level is generally expressed in $\mathrm{mg} / \mathrm{dL}$. Nevertheless, the erythrocyte membrane cholesterol level will not be expressed in this unit. In this case, erythrocyte membrane cholesterol level would be expressed in $\mathrm{mg}$ of cholesterol per gram of the hemoglobin.

\section{Hemoglobin level}

The concentration of hemoglobin was determined by the Drabkin's method. The method involves oxidation of the hemoglobin then conversion by potassium cyanide into cyan methemoglobin. The absorbance of cyan methemoglobin measured with a spectrophotometer at $540 \mathrm{~nm}$ is directly proportional to the concentration of hemoglobin [18].

\section{Determination of reference values of samples}

These values allow us to interpret the results from patients. Reference values are defined as the set of values representing $95 \%$ of the distribution of a variable. From the 20 control subjects, the reference values was determined by the mean (M) and the standard deviation (S) as follows: $\mathrm{M} \pm 1.96 \mathrm{~S}$ [19].

\section{Statistical analysis of the results}

The Student's test was performed to compare the erythrocyte membrane cholesterol levels of the controls group and subjects group. The data were computed by Microsoft Excel and analyzed with Microsoft SPSS 15 software.

\section{Results}

\section{Isoelectric focusing}

The results of isoelectric focusing on 20 controls showed that 17 (85\%) had normal hemoglobin status "AA" and 3 (15\%) had heterozygote abnormal hemoglobin status "AS".

There was no homogeneity "SS".

\section{Screening of hemogram in the control group}

Since three controls were excluded because of their abnormal hemoglobin status (AS), we performed the hemogram for the remaining 17 controls (AA). The results revealed that only 16 control subjects had normal hemogram. Thus 
16 control subjects were selected for this study.

\section{Evaluation of erythrocyte membrane cholesterol of control}

In the control group, the erythrocyte membrane cholesterol was assessed on 16 samples with a normal hemogram. The erythrocyte membrane cholesterol levels were $17.55 \pm 1.96 \mathrm{mg}$ of cholesterol/g of hemoglobin.

Thus, the results allowed us to define the range of reference values of erythrocyte membrane cholesterol as follows $(\alpha=0.05): 17.55 \pm 3.83 \mathrm{mg}$ of cholesterol/g of hemoglobin. This corresponds to the following reference interval: 13.72 to $21.38 \mathrm{mg}$ of cholesterol/g of hemoglobin.

Evaluation of erythrocyte membrane cholesterol of sickle cell patient

In sickle cells group, the erythrocyte membrane cholesterol level of 50 subjects was $11.58 \pm 2.98 \mathrm{mg}$ cholesterol/g of hemoglobin. These results were compared with the reference interval established from the controls in this study. Table 1 shows the results of this comparison.

\section{Statistical analysis of the data}

Using the Student test, the erythrocyte membrane cholesterol levels in the control group were compared with those of the sickle cell group. This test compared the means of these two groups. The results of this statistical analysis are shown in Table 2.

\section{Discussion}

The evaluation of erythrocyte membrane cholesterol level in sickle cell patients was the main goal of this study. This study was performed with two groups: a control group and a sickle cell patients group. The hemogram and the isoelectric focusing were used to select the control subjects. Only 16 samples out of 20 met the criteria and then were retain in this study. The erythrocyte membrane cholesterol was evaluated in the group of control and sickle cell patients. The results were expressed in $\mathrm{mg}$ of cholesterol/g of hemoglobin.

The result in Table 1 shows that 38/50 sickle cell patients (76\%) had levels of erythrocyte membrane cholesterol under the reference interval established in

Table 1. Comparison of the membrane cholesterol level erythrocyte of sickle cell patient with the reference.

\begin{tabular}{cccc}
\hline & \multicolumn{2}{c}{ Erythrocyte membrane cholesterol level in mg/g of Hb } \\
\hline Number of sickle cell patient & 38 & 12 & 0 \\
Range of value & $<13.72$ & $13.73-21.38$ & $>21.38$ \\
\hline
\end{tabular}

Table 2. Results of the statistical analysis.

\begin{tabular}{ccccc}
\hline \multirow{2}{*}{ Parameters } & \multicolumn{2}{c}{ Erythrocyte membrane cholesterol level in $\mathrm{mg} / \mathrm{g}$ of $\mathrm{Hb}$} \\
\cline { 2 - 4 } & Control group & Sickle cell patients & \\
& $17.55 \pm 1.96$ & $11.58 \pm 2.98^{*}$ & & \\
value & 3.83 & 8.85 & 7.42 & 0.044 \\
Variance & & & & \\
\hline
\end{tabular}


this study (13.72 $\mathrm{mg}$ of cholesterol/g of $\mathrm{Hb}$ ). The Table 1 also shows that 12/50 (24\%) had a level of membrane cholesterol within the interval.

Statistical analysis $(\alpha=0.05)$ using Student's test in Table 2 , shows a significant difference between the erythrocyte membrane cholesterol levels of control group and those of sickle cell patients group $(\mathrm{p}=0.044)$. Our study reveals that erythrocyte membrane cholesterol level in sickle cell patients is lower than the control. As stated above, the cholesterol strengthens the membrane. The decrease of membrane cholesterol level in sickle cell patients is considered to be one of the factors which could explain the hemolytic nature of the anemia observed in sickle cell patients. This decrease could be part of the worsening hemolysis or the increase in the number of hemolytic crisis.

According to a study carried out with cell lines that did not synthesize cholesterol, it was observed that after culture, these cells rapidly undergo lysis because of the very great fragility of their membrane [9] [20]. This study confirms the crucial role of cholesterol in the cell membrane. However, the same experiment carried out in the presence of cholesterol in the culture medium showed inhibition of cytolysis.

Cholesterol is an essential element in maintaining the fluidity and stability of the membrane in general. As the quantity of membrane cholesterol increases, the membrane fluidity also increases while the fragility decreases. Conversely, when the amount of membrane cholesterol decreases, the fluidity decreases as well but the fragility increases.

The erythrocyte membrane cholesterol level found in sickle cell disease is low compared to the reference values set in this study. This has an impact on the membrane fluidity which is reduced. The increase in membrane fluidity results in a decrease in the rigidity of the plasma membrane of erythrocytes and a decrease in the fragility of the membrane [6] [10]. The decreased fluidity exposes erythrocytes to hemolysis. We believe that the decreased erythrocytes membrane cholesterol levels in sickle cell patients could be considered as one of the major factors that contribute to the hemolysis frequently observed in sickle cell disease.

\section{Conclusion}

Our study was designed for assessing the membrane cholesterol levels in sickle cell patients as one the essential factors of membrane fluidity. The results found showed that the erythrocyte membrane cholesterol levels in sickle cell patients were low. The decrease in erythrocyte membrane cholesterol levels results in a decrease in membrane fluidity, making the plasma membrane more fragile. This may justify the hemolytic anemia encountered in sickle cell disease. However, the weakness of this study lies in the small number of samples and also in the fact that the decrease in the level of membrane cholesterol can have others etiologies.

\section{Conflicts of Interest}

The authors declare no conflicts of interest regarding the publication of this paper. 


\section{References}

[1] Bardakdjian, J. and Wajcman, H. (2004) Epidemiology of Sickle Cell Anemia. La Revue du Praticien, 12, 859-861.

[2] Girot, R., Begué, P. and Galcteros, F. (2003) Sickle Cell Disease. Editions John Libbey Eurotx, Paris.

[3] Rombi, M. (2007) Sickle Cell Disease and Thalassemia: Dietetic Advice for People with This Disease. Alpeneditions.

[4] Baledent, F. (2006) Genetics and Biological Diagnosis of Sickle Cell Disease. Biologist, Center Hospitalier, France.

[5] Montalembert, M. (2007) Erythrocyte Exchanges in Sickle Cell Patients. Hematology, 13, 243-249.

[6] Sherewood, L., Klandorf, H. and Yancey, P. (2016) Animal Physiology. Deboek, Paris.

[7] Geoffrey, M. (1999) The Cell: A Molecular Approach. Deboek, Paris.

[8] Lodish, H. and Darnell, J.E. (1997) Molecular Biology of the Cell. Debeok, Paris.

[9] Maillet, M. (2006) Biology of the Cell. Elsevier Masson, Amsterdam.

[10] Martini, M.C. (2011) Introduction to Dermopharmacy and Cosmetology. Lavoisier, Paris.

[11] Chen, J.Y., Galwankar, N.S., Emch, H.N., Menon, S.S., Cortes, C., Thurman, J.M., Merrill, S.A., Brodsky, R.A. and Ferreira, V.P. (2020) Properdin Is a Key Player in Lysis of Red Blood Cells and Complement Activation on Endothelial Cells in Hemolytic Anemias Caused by Complement Dysregulation. Frontiers in Immunology, 11, 1460. https://doi.org/10.3389/fimmu.2020.01460

[12] Vaille-Perret, E., Motta, C. and Jalenques, I. (2002) Clinical Development and Evolution of the Membrane Fluidity in Schizophrenic Patients Treated by Neuroleptics. Annales Médico-Psychologiques, Psychiatric Review, 160, 58-66. https://doi.org/10.1016/S0003-4487(01)00131-7

[13] Bernard, J., Levy, J.P., Clauvel, J.P., Rain, J.D. and Varet, B. (1976) Summary of Hematology. 3rd Edition, Masson, Paris.

[14] Dreyfus, D., Breton-Gorius, J., Rochant, H., Reyes, F. and Vernant, J.P. (1984) Hématologie. Flammarion Medicine-Sciences, Paris.

[15] Longpré, B. and Schapcott, D. (1983) Anemias' Basic Concepts. Masson, Paris.

[16] Chemistry Laboratory (2007) Manual of Procedure for Separation of Hemoglobins by Isoelectric Focusing. Erasme Hospital, Brussels.

[17] Package Leaflet for Cholesterol Assay. Human.

[18] Bernard, S. (1985) Clinical Biochemistry: Laboratory Instruments and Techniques. Maloine, Paris.

[19] Mwelo, N., Diyi, L., Ekofembe, P., Nzingula, P., Mpanzimu, F., Itumine, M. and Engo, B. (2016) Test to Determine the Reference Intervals of Serum Proteins in the Congolese Population. Research Journal, 3, 1537. https://doi.org/10.13070/rs.fr.3.1537

[20] Bernecker, C., Köfeler, H., Pabst, G., Trötzmüller, M., Kolb, D., Strohmayer, K., Trajanoski, S., Holzapfel, G.A., Schlenke, P. and Dorn, I. (2019) Cholesterol Deficiency Causes Impaired Osmotic Stability of Cultured Red Blood Cells. Frontiers in Physiology, 10, 1529. https://doi.org/10.3389/fphys.2019.01529 